\title{
EXTERNAL ECONOMIES AND INTERNATIONAL TRADE REDUX: COMMENT*
}

\author{
Gary Lyn And Andrés Rodríguez-Clare ${ }^{\dagger}$
}

May 13, 2013

\begin{abstract}
Recently in this Journal Grossman and Rossi-Hansberg (2010) proposed a novel way to think about the implications of international trade in the presence of national external economies at the industry level. Instead of perfect competition and two industries, GRH assume Bertrand competition and a continuum of industries. GRH conclude that the equilibrium is unique if transport costs are low, that there is no trade for high transport costs, and that there is no equilibrium in pure strategies when transport costs are intermediate. In this note we reexamine the equilibrium analysis under different transport costs for a single industry (partial equilibrium) version of GRH's model. We confirm many of GRH's results, but also find that there are circumstances under which there are multiple equilibria, including equilibria in which trade patterns run counter to "natural" comparative advantage, and also find that there is a profitable deviation to the mixed-strategy equilibrium postulated by GRH for intermediate trading costs. We propose an alternative set of strategies for this case and establish that they constitute an equilibrium.

JEL code: F10

Total word count: 2,807
\end{abstract}

${ }^{*}$ We thank Kalyan Chatterjee, Gene Grossman, Vijay Krishna, Konstantin Kucheryavyy, Esteban RossiHansberg, Adam Slawski, and an anonymous referee for helpful comments. A special thanks also to James Graham-Eagle and Donald Richards for invaluable insights.

†549 Evans Hall \#3880, Berkeley, CA 94720-3880. Tel: (510) 642-0822 Fax: (510) 642-6615 Email: andres@econ.berkeley.edu 


\section{Introduction}

Grossman and Rossi-Hansberg (2010, henceforth GRH) propose a novel way to think about the implications of international trade in the presence of national external economies at the industry level. Instead of a model with two industries and perfect competition, as in the standard treatment in the literature, GRH postulate a model with a continuum of industries and Bertrand competition. These authors argue that with these alternative assumptions the "pathologies" of the standard treatment are eliminated. In particular, the equilibrium is typically unique with trade patterns consistent with "natural" comparative advantage ${ }^{1}$. This is most clearly the case with frictionless trade, which the authors use to make their main points. The authors then explore how the results change when transportation costs are positive. They show that the previous results remain valid when trading costs are low enough, while for high enough trading costs the equilibrium entails no trade. However, there is a range of high trading costs for which there exists no equilibrium in pure strategies. For this case, GRH postulate a mixed-strategy equilibrium in which firms in the country with the comparative advantage mix over two strategies: the "global strategy", in which firms target the world market with a pair of prices (one for the home market and one for the foreign market), and the "domestic strategy", in which firms target only the domestic market. Firms in the other country pursue a pure strategy in which they target their domestic market.

In this note we show that there is a profitable deviation to the mixed-strategy equilibrium postulated by GRH, and then propose an alternative set of strategies and establish that they constitute an equilibrium. The main difference is that firms in the country with the comparative advantage, when pursuing the global strategy, randomize across a continuum of prices for the domestic market rather than posting a single price for that market. However, this mixed-strategy equilibrium applies only to an industry in which a country has a strong enough ("superior") comparative advantage. Otherwise, firms in the country without the

\footnotetext{
${ }^{1}$ In a Ricardian context, this means that the pattern of specialization is consistent with the ranking of relative (exogenous) productivities when measured at a common scale of production.
} 
comparative advantage find it profitable to deviate and target the global market. Characterizing the equilibrium for the case in which comparative advantage is not "superior" goes beyond the scope of this comment.

As part of this note, we also provide a formal analysis of the equilibrium configurations under different transport costs for a single industry that exhibits Marshallian externalities. We confirm GRH's result that for low trading costs there is complete specialization, for high enough trading costs there is no trade, and that there is a range of high trading costs for which there is no equilibrium in pure strategies. However, in contrast to GRH, we demonstrate that when transport costs are low, the equilibrium entails complete specialization, but is not necessarily unique. This implies that trade patterns need not be consistent with "natural" comparative advantage, and hence, as in the standard treatment in the literature, national external economies at the industry level still offer a theoretical basis for industrial policy, a point which we develop in Lyn and Rodríguez-Clare (2013).

\section{The Model}

For our purposes we consider a partial equilibrium version of the model presented by GRH. This allows for greater expositional simplicity, while capturing all the main features of the problem at hand. ${ }^{2}$ There are two countries, Home and Foreign, labor is the only factor of production, wages are exogenous and fixed at $w$ and $w^{*}$, and we focus on a single good with demand curves $x(p)$ and $x^{*}\left(p^{*}\right)$ that have a unitary price elasticity, so that $x(p)=\frac{E}{p}$ and $x^{*}\left(p^{*}\right)=\frac{E^{*}}{p^{*}}$, where $E$ and $E^{*}$ are total expenditure levels. The production technology has increasing returns to scale due to external economies at the local level. In Home $\frac{a}{X^{\phi}}$ units of labor are required to produce a unit of output, where $a>0$ is an exogenous productivity parameter, $X$ is the total production of the good in Home net of any trade costs (see below),

\footnotetext{
${ }^{2}$ In Lyn and Rodríguez-Clare (2013) we explore the implications of our results for industrial policy and the gains from trade in a full general equilibrium analysis.
} 
and $0<\phi<\frac{1}{2} \cdot{ }^{3}$ Similarly, the labor unit requirement in Foreign is $\frac{a^{*}}{\left(X^{*}\right)^{\phi}}$. There are two identical firms in Home and two identical firms in Foreign. Transport costs are of the "iceberg" type, so that delivering a unit of the good from one country to the other requires shipping $t>1$ units. $^{4}$ Markets are segmented, so that firms can set arbitrarily different prices across both markets. Firms engage in Bertrand competition in each market. For simplicity we restrict the analysis to the case in which demand is symmetric in the two countries, $E=E^{*}$. Without loss of generality we set $E=E^{*}=1$.

As in GRH, we study three types of equilibria: complete specialization (i.e., firms from one country supply both markets); mixed strategy equilibria (i.e., firms from one country randomize over which markets to serve and the price to charge, while firms from the other country offer to serve their own market at the autarky price); no trade (i.e., firms from each country serve only their own market). All proofs are in the online Appendix.

\subsection{Complete specialization equilibrium}

Let $p_{0}$ be defined implicitly by

$$
p_{0}=\frac{w a}{\left(x\left(p_{0}\right)+x^{*}\left(t p_{0}\right)\right)^{\phi}} .
$$

We will use $x$ and $x^{*}$ as shorthand for $x\left(p_{0}\right)$ and $x^{*}\left(t p_{0}\right)$, respectively.

\section{Lemma 1 If}

$$
\left[\frac{w a}{\left(x+x^{*}\right)^{\phi}}-\frac{w^{*} a^{*} t}{\left(x+x^{*}\right)^{\phi}}\right] x+\left[\frac{w a t}{\left(x+x^{*}\right)^{\phi}}-\frac{w^{*} a^{*}}{\left(x+x^{*}\right)^{\phi}}\right] x^{*} \leq 0
$$

\footnotetext{
${ }^{3}$ Given our primitives, the assumption that $\phi<\frac{1}{2}$ implies profits are increasing in prices - a crucial point when deriving the equilibrium conditions.

${ }^{4}$ By assuming $X$ is total production net of trade costs we are essentially treating "iceberg" transport costs as "true" costs. This is consistent with the assumptions in GRH. Treating $X$ as gross production would be more consistent with a literal interpretation of some production $(t-1)$ melting away in transit.
} 
and

$$
\left[\frac{w a t}{\left(x+x^{*}\right)^{\phi}}-\frac{w^{*} a^{*}}{\left(x^{*}\right)^{\phi}}\right] x^{*} \leq 0,
$$

then there is an equilibrium where both markets are supplied by Home firms, with prices $p_{0}$ and $p_{0}^{*} \equiv t p_{0}$ at Home and Foreign, respectively.

In the proof of this lemma we first establish that profits are increasing in prices. This implies that the best possible deviation entails "shaving" prices $p_{0}$ and $p_{0}^{*}$, i.e., it is never optimal to charge strictly lower prices than $p_{0}$ and $p_{0}^{*}$. Since prices $p_{0}$ and $p_{0}^{*}=t p_{0}$ imply that Home firms make zero profits in both markets, it follows that a Home firm cannot make positive profits with any alternative set of prices, implying that that there is no profitable deviation for a Home firm. The proof then turns to Foreign firms, establishing that (i) firms from Foreign do not make positive profits by taking over the world market by undercutting Home firms in both markets, and that (ii) firms from Foreign do not make positive profits by displacing Home firms from the Foreign market. Condition (i) is a guaranteed by (2) and condition (ii) is guaranteed by (3).

To proceed, let $\beta=\frac{w a}{w^{*} a^{*}}, g(t) \equiv \frac{t+t^{-1}}{2}$ and $h(t) \equiv t^{-1}(1+t)^{\phi}$. It is easy to show that (2) and (3) are equivalent to $\beta \leq g(t)$ and $\beta \leq h(t)$, respectively. Let $g^{*}(t) \equiv \frac{1}{g(t)}$ and $h^{*}(t) \equiv \frac{1}{h(t)}$. Let $\widetilde{t}$ be implicitly defined by $g(\widetilde{t})=h(\widetilde{t})$, let $t_{C S}(\beta)$ and $t_{C S}^{*}(\beta)$ be implicitly defined by $\beta=h\left(t_{C S}\right)$ and $\beta=h^{*}\left(t_{C S}^{*}\right)$, respectively, and let $t_{0}^{*}(\beta)$ be implicitly defined by $\beta=g^{*}\left(t_{0}^{*}\right)$. We say that Home has a "strong" comparative advantage if $\beta<g^{*}(\widetilde{t})$ while we say that Home has a "weak" comparative advantage if $g^{*}(\widetilde{t}) \leq \beta<1$.

Proposition 1 Assume that $\beta<1$ (so that Home has a comparative advantage). If Home has a strong comparative advantage, then for $t \in\left[1, t_{C S}(\beta)\right]$ there is a unique equilibrium with complete specialization, and this equilibrium has Home serving both markets. If Home has a weak comparative advantage, then for $t \in\left[1, t_{0}^{*}(\beta)\right] \cup\left[t_{C S}^{*}(\beta), t_{C S}(\beta)\right]$ there is a unique equilibrium with complete specialization, and this equilibrium has Home serving both markets, whereas for $t \in\left[t_{0}^{*}(\beta), t_{C S}^{*}(\beta)\right]$ there are two complete specialization equilibria, one with Home 
serving both markets, and another with Foreign serving both markets (See Figure I).

This Proposition confirms GRH's result that for any industry there are transport costs which are low enough that the equilibrium is unique and entails complete specialization. However, this proposition also shows that there are conditions under which multiple complete specialization equilibria arise. The reason for this multiplicity is that trade costs create a wedge in prices, thereby making the distribution of sales across countries different for each equilibria: in the equilibrium in which Home firms capture the global market, prices are low in Home and high in Foreign, and the opposite happens in the equilibrium in which Foreign firms capture the market. This makes it harder for a deviant firm to make profits.

For concreteness, imagine that $t \in\left[t_{0}^{*}(\beta), t_{C S}^{*}(\beta)\right]$ and Home has a weak comparative advantage, and consider the equilibrium in which Foreign firms supply the world market. A Home firm may contemplate shaving prices in both markets in order to capture the global market. Since comparative advantage is weak, however, this deviation entails losses from sales overseas because of the need to sell at a low price in the Foreign market together with the existence of trade costs. The realization of economies of scale thanks to capturing the global market leads to lower costs and hence profits from domestic sales, but this is not enough to compensate for the losses incurred from sales overseas. The deviation is then not profitable, so a situation in which firms from the country without the comparative advantage dominate the global market is an equilibrium. An important implication is that for this case trade patterns need not be consistent with "natural" comparative advantage.

\subsection{Equilibrium with no trade}

Let $p_{A}$ and $p_{A}^{*}$ be defined implicitly by $p_{A}=\frac{w a}{\left(x\left(p_{A}\right)\right)^{\phi}}$ and $p_{A}^{*}=\frac{w^{*} a^{*}}{\left(x^{*}\left(p_{A}^{*}\right)\right)^{\phi}}$, respectively. We will use $x_{A}$ and $x_{A}^{*}$ as shorthand for $x\left(p_{A}\right)$ and $x^{*}\left(p_{A}^{*}\right)$, respectively. 


\section{Lemma 2 If}

$$
\left[\frac{w a}{\left(x_{A}\right)^{\phi}}-\frac{w a}{\left(x_{A}+x_{A}^{*}\right)^{\phi}}\right] x_{A}+\left[\frac{w^{*} a^{*}}{\left(x_{A}^{*}\right)^{\phi}}-\frac{w a t}{\left(x_{A}+x_{A}^{*}\right)^{\phi}}\right] x_{A}^{*} \leq 0
$$

and

$$
\left[\frac{w a}{\left(x_{A}\right)^{\phi}}-\frac{w^{*} a^{*} t}{\left(x_{A}+x_{A}^{*}\right)^{\phi}}\right] x_{A}+\left[\frac{w^{*} a^{*}}{\left(x_{A}^{*}\right)^{\phi}}-\frac{w^{*} a^{*}}{\left(x_{A}+x_{A}^{*}\right)^{\phi}}\right] x_{A}^{*} \leq 0
$$

then there is an equilibrium with no trade.

Recall that the best possible deviation entails "shaving" prices. Hence, (4) guarantees that a deviation by a Home firm to target the global market is unprofitable, while (5) assures the same regarding a Foreign deviant firm. Let $f(z) \equiv \frac{2\left(1+z^{\frac{1}{1-\phi}}\right)^{\phi}-1}{z^{\frac{1}{1-\phi}}}$ and $t_{N T}(\beta) \equiv f(\beta)$ and $t_{N T}^{*}(\beta) \equiv f\left(\frac{1}{\beta}\right)$. Using our assumptions on primitives we can rewrite (4) and (5) as $t \geq t_{N T}(\beta)$ and $t \geq t_{N T}^{*}(\beta)$, respectively.

Proposition 2 An equilibrium with no trade exists if and only if

$$
t \geq \max \left\{t_{N T}(\beta), t_{N T}^{*}(\beta)\right\}
$$

Letting $l(t) \equiv\left(t_{N T}\right)^{-1}(t)$ and $l^{*}(t) \equiv\left(t_{N T}^{*}\right)^{-1}(t)$, the conditions $t \geq t_{N T}(\beta)$ and $t \geq$ $t_{N T}^{*}(\beta)$ are equivalent to $\beta \geq l(t)$ and $\beta \leq l^{*}(t)$, respectively. See Figure II.

\subsection{Equilibrium with mixed strategies}

As in GRH, our analysis confirms that there is a range of high transport costs for which there is no equilibrium in pure strategies. For this case, condition (2) is satisfied but conditions (3) and (4) are not - the violation of (3) implies that complete specialization in Home is not an equilibrium because Foreign firms would deviate to displace Home firms from their local market, and the violation of (4) implies that no trade is not an equilibrium because Home firms would deviate and seize both markets. Figure III shows how this corresponds to the range of transport costs $t \in\left(t_{C S}(\beta), t_{N T}(\beta)\right)$ for $\beta \leq 1$. 
GRH argue that for this range of transport costs there exists an equilibrium in which Home firms randomize between a strategy that leads to only sales in Home (the local strategy) and a strategy that ensures sales in both markets (the global strategy). The challenge in constructing such an equilibrium is that Home sales are profitable while sales in Foreign entail a loss, so Home firms would be tempted to shave the Home price, thereby capturing all the profits associated with local sales while sharing the losses in the Foreign market. In fact, the equilibrium proposed by GRH can be shown to allow for a profitable deviation along these lines.

\subsubsection{Profitable Deviation to the Mixed Strategy proposed by GRH}

Let $\Phi(p) \equiv\left[p-\frac{w a}{\left(x(p)+x^{*}\left(p_{A}^{*}\right)\right)^{\phi}}\right] x(p)$, and $\Phi^{*}(p) \equiv\left[p_{A}^{*}-\frac{w a t}{\left(x(p)+x^{*}\left(p_{A}^{*}\right)\right)^{\phi}}\right] x^{*}\left(p_{A}^{*}\right)$, where $\Phi(p)$ and $\Phi^{*}(p)$ are the profits made by Home firms in Home and Foreign, respectively, given prices $p$ in Home and $p_{A}^{*}$ in Foreign. GRH propose an equilibrium in which Foreign firms do not export and charge a price $p_{A}^{*}$ while Home firms mix between a local strategy (no exports) with Home price $p_{A}$ and a global strategy, where firms shave price $p_{A}^{*}$ in Foreign and set a price $p_{G}$ in Home that satisfies $\Phi\left(p_{G}\right)+\Phi^{*}\left(p_{G}\right)=0$. Let

$$
\pi\left(p, p^{*}\right) \equiv\left[p-\frac{w a}{\left(x(p)+x^{*}\left(p^{*}\right)\right)^{\phi}}\right] x(p)+\left[p^{*}-\frac{w a t}{\left(x(p)+x^{*}\left(p^{*}\right)\right)^{\phi}}\right] x^{*}\left(p^{*}\right)
$$

denote the global profits for Home firms given prices $p$ and $p^{*}$, and note for future reference that $\pi\left(p, p_{A}^{*}\right)=\Phi(p)+\Phi^{*}(p)$ while the definition of $p_{G}$ entails $\pi\left(p_{G}, p_{A}^{*}\right)=0$.

We proceed in two steps. As a first step, we show that $\Phi\left(p_{G}\right)>0$ and $\Phi^{*}\left(p_{G}\right)<0$ implying that Home firms make profits in Home and losses in Foreign. Consider the price $p_{0}$. The violation of condition (3) implies that $t p_{0}>p_{A}^{*}$, so charging $t p_{0}$ in Foreign cannot be part of an equilibrium. ${ }^{5}$ Since profits are increasing in prices (i.e., $\pi_{1}, \pi_{2}>0$ ) and

\footnotetext{
${ }^{5}$ To see this, note that the violation of (3) implies $\frac{w^{*} a^{*}}{\left(x^{*}\left(t p_{0}\right)\right)^{\phi}}<\frac{w a t}{\left(x\left(p_{0}\right)+x^{*}\left(t p_{0}\right)\right)^{\phi}}=t p_{0}$, while we know that $p_{A}^{*}=\frac{w^{*} a^{*}}{\left(x^{*}\left(p_{A}^{*}\right)\right)^{\phi}}$. Let $f(p) \equiv \frac{w^{*} a^{*}}{\left(x^{*}(p)\right)^{\phi}}$. Then we have $f\left(t p_{0}\right)<t p_{0}$ and $f\left(p_{A}^{*}\right)=p_{A}^{*}$. Since $f(p)$ intersects $p$ only once and from above (by Assumption $\phi<\frac{1}{2}$ ) then it follows that $f(p)<p$ if and only if $p>p_{A}^{*}$. This
} 
$\pi\left(p_{0}, \tau p_{0}\right)=0$, then $\pi\left(p_{G}, p_{A}^{*}\right)=0$ with $p_{A}^{*}<t p_{0}$ requires $p_{G}>p_{0}$. Note also that $t p_{0}>p_{A}^{*}$ implies $\Phi^{*}\left(p_{0}\right)<0$ since it would be zero if firms could charge $t p_{0}$ in Foreign but now they must charge an even lower price $p_{A}^{*}$. Since $\Phi^{*}(p)$ is decreasing (i.e., profits in Foreign are decreasing in the Home price) and $p_{G}>p_{0}$, we then conclude that $\Phi^{*}\left(p_{G}\right)<0$ and from $\Phi\left(p_{G}\right)+\Phi^{*}\left(p_{G}\right)=0$ we get $\Phi\left(p_{G}\right)>0$.

As a second step, we show that $\Phi^{*}\left(p_{G}\right)<0$ implies that there exists a profitable deviation to the proposed strategy. Let the probability of choosing the local strategy be $q$, and consider a deviation to a pure strategy with price in Foreign equal to $p_{A}^{*}$ and the local price just below $p_{G}$, say at $p^{\prime}$ just below $p_{G}$. The profits under the deviation are $q\left[\Phi\left(p^{\prime}\right)+\Phi^{*}\left(p^{\prime}\right)\right]+$ $(1-q)\left[\Phi\left(p^{\prime}\right)+\frac{\Phi^{*}\left(p^{\prime}\right)}{2}\right] \cdot{ }^{6}$ Since $p^{\prime} \approx p_{G}$ then $\Phi\left(p^{\prime}\right)+\Phi^{*}\left(p^{\prime}\right) \approx 0$ and hence expected profits under the deviation are $(1-q) \frac{\Phi\left(p^{\prime}\right)}{2}>0$. Intuitively, by charging a slightly lower price in the domestic market, a Home firm secures all the profits from Home sales while not incurring more losses in Foreign.

\subsubsection{An Alternative Mixed Strategy}

We now propose an alternative mixed strategy equilibrium that holds when Home has a "superior comparative advantage", where we use "superior" rather than "strong" (used before) because the two concepts are different. We say that Home has a superior comparative advantage if $\beta<l^{*}(\widehat{t})$, where $\widehat{t}$ is defined implicitly by $h(\widehat{t})=l^{*}(\widehat{t})$ (see Figure III).

Assume again that (2) is satisfied, whereas (3) and (4) are both violated. For this case, we propose the following equilibrium. As in the equilibrium proposed by GRH, Foreign firms do not export and charge a price $p_{A}^{*}$, while with probability $q$ Home firms pursue the local strategy of not exporting and charging a local price of $p_{A}$. The only difference is in the global strategy of Home firms (pursued with probability $1-q$ ): just as in GRH this entails shaving price $p_{A}^{*}$ in the Foreign market, however the domestic price $p$ is now drawn from the

immediately implies that $t p_{0}>p_{A}^{*}$.

${ }^{6}$ Note that the "2" in the expression $\frac{\Phi^{*}\left(p^{\prime}\right)}{2}$ arises because of our assumption of two firms in each market. 
distribution

$$
F(p)=\frac{1}{M(p)} \frac{\int_{s}^{p} \zeta(y) M(y) d y}{\int_{s} \zeta(y) M(y) d y}+\frac{M(p)-1}{M(p)},
$$

with support $p \in\left[s, p_{A}\right]$, where

$$
\zeta(y) \equiv \frac{\Phi^{\prime}(y)+\Phi^{* \prime}(y)}{\Phi(y)} \text {, and } M(y) \equiv \exp \left(\int_{s}^{y} \frac{\Phi^{\prime}(t)+\frac{\Phi^{* \prime}(t)}{2}}{\Phi(t)} d t\right)
$$

It is easy to verify that $F(s)=0, F\left(p_{A}\right)=1$ and $F^{\prime}(p)>0$. The mixing probability $q$ is given by,

$$
q=\left(1+\int_{s}^{p_{A}} \zeta(y) M(y) d y\right)^{-1}
$$

Finally, $s$ is determined implicitly by (8) and

$$
\Phi(s)+\left(q+\frac{1-q}{2}\right) \Phi^{*}(s)=0
$$

Formally,

Proposition 3 Assume that Home has a superior comparative advantage, i.e., $\beta<l^{*}(\widehat{t})$, where $\widehat{t}$ is defined implicitly by $h(\widehat{t})=l^{*}(\widehat{t})$. For $t \in\left(t_{C S}(\beta), t_{N T}(\beta)\right)$ the equilibrium entails Foreign firms charging $p_{A}^{*}$ in Foreign and making no sales in Home, and Home firms following a mixed strategy where with probability q they follow the "local strategy" according to which they charge $p_{A}$ in Home and make no sales in Foreign and with probability $1-q$ they follow the "global strategy" according to which they shave $p_{A}^{*}$ in Foreign and charge a price $p \in\left[s, p_{A}\right]$ in Home according to the distribution $F(p)$ in (7), with $q$ and s satisfying (8) and (9).

University of Massachusetts Lowell

University of CAlifornia Berkeley AND NBER 


\section{References}

Ethier, Wilfred J., "Decreasing Costs in International Trade and Frank Graham's Argument for Protection," Econometrica, 50 (1982a), 1243-1268.

Grossman, Gene M., and Esteban Rossi-Hansberg, "External Economies and International Trade: Redux," Quarterly Journal of Economics, 125 (2010), 829-858.

Lyn, Gary A., and Andrés Rodríguez-Clare, "Marshallian Externalities, Comparative Advantage and International Trade," Working Paper, (2013). 


\section{$3 \quad$ Figures}

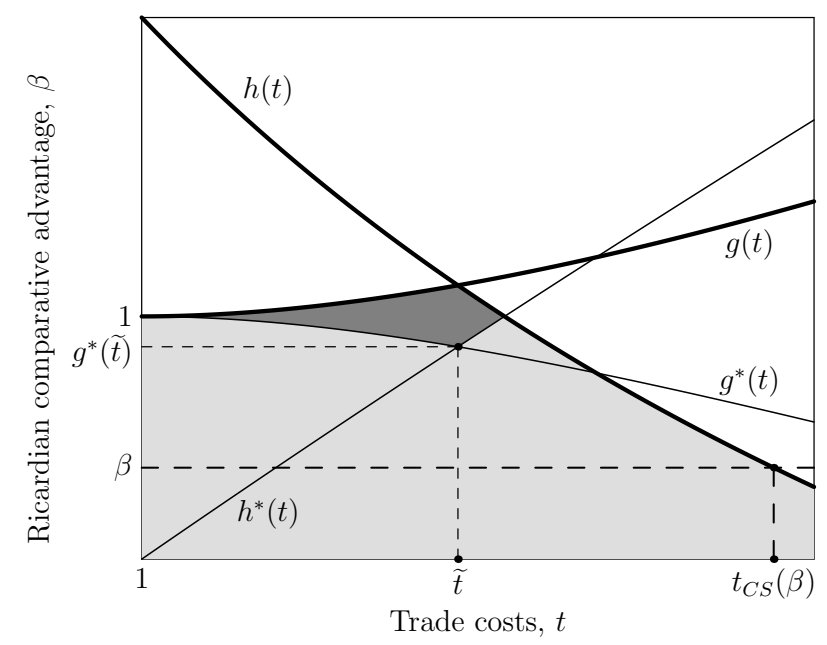

(a) Strong comparative advantage

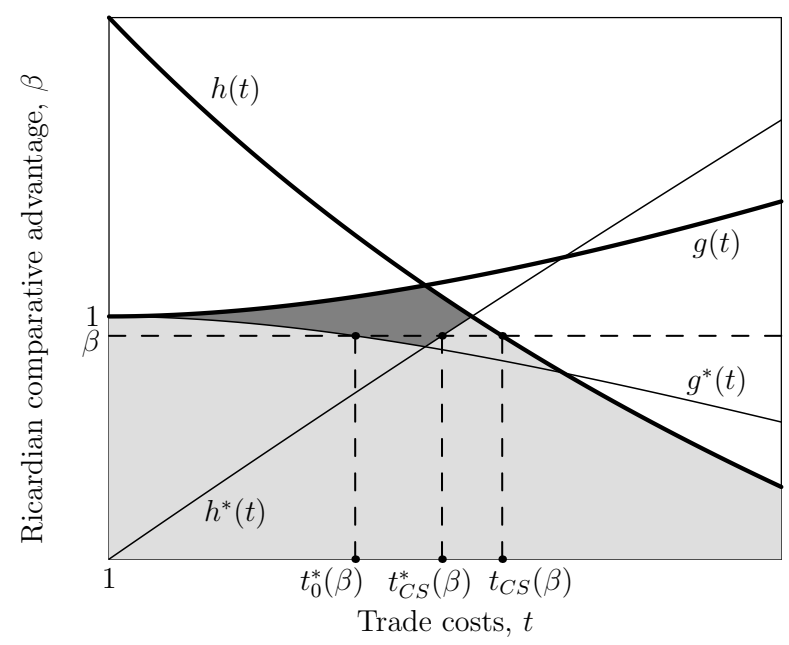

(b) Weak comparative advantage

Figure I: Complete specialization equilibria with low trade costs, $\phi=0.3$ 


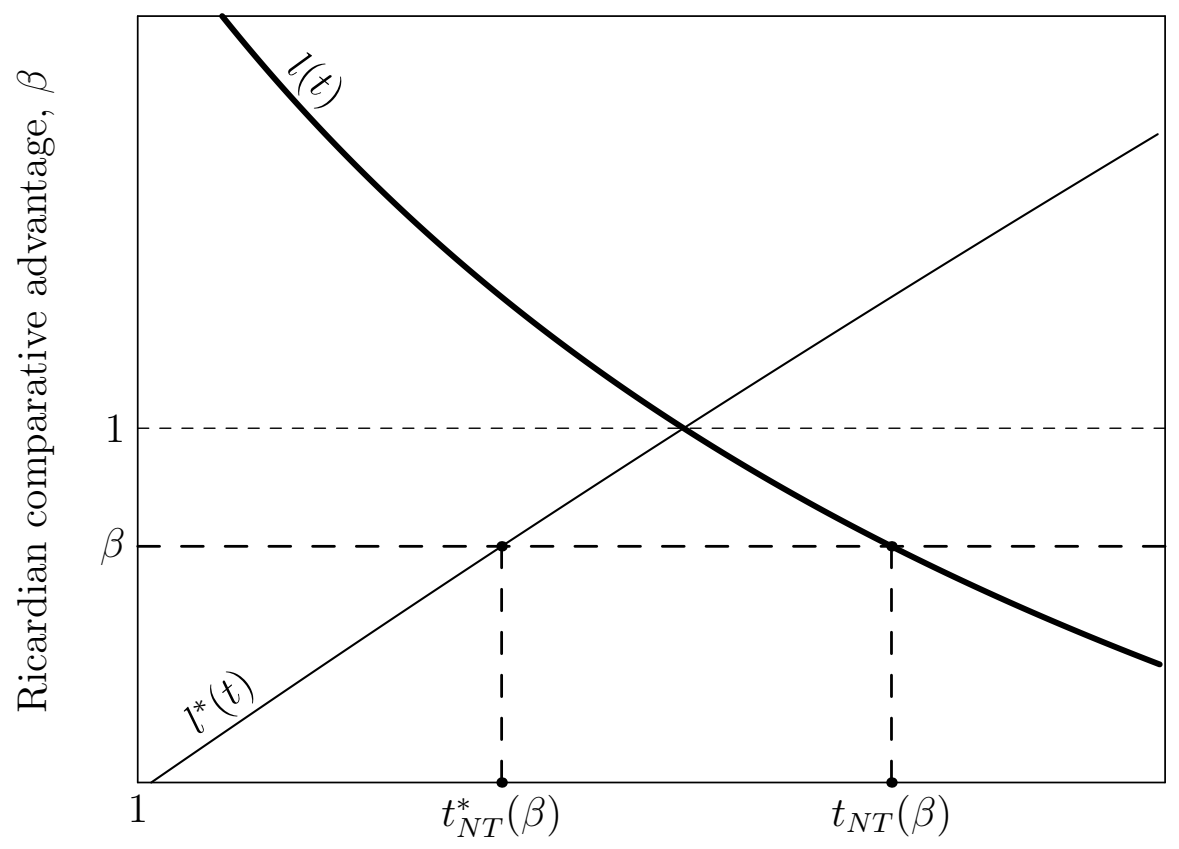

Trade costs, $t$

Figure II: Equilibrium with no trade, $\phi=0.3$ 


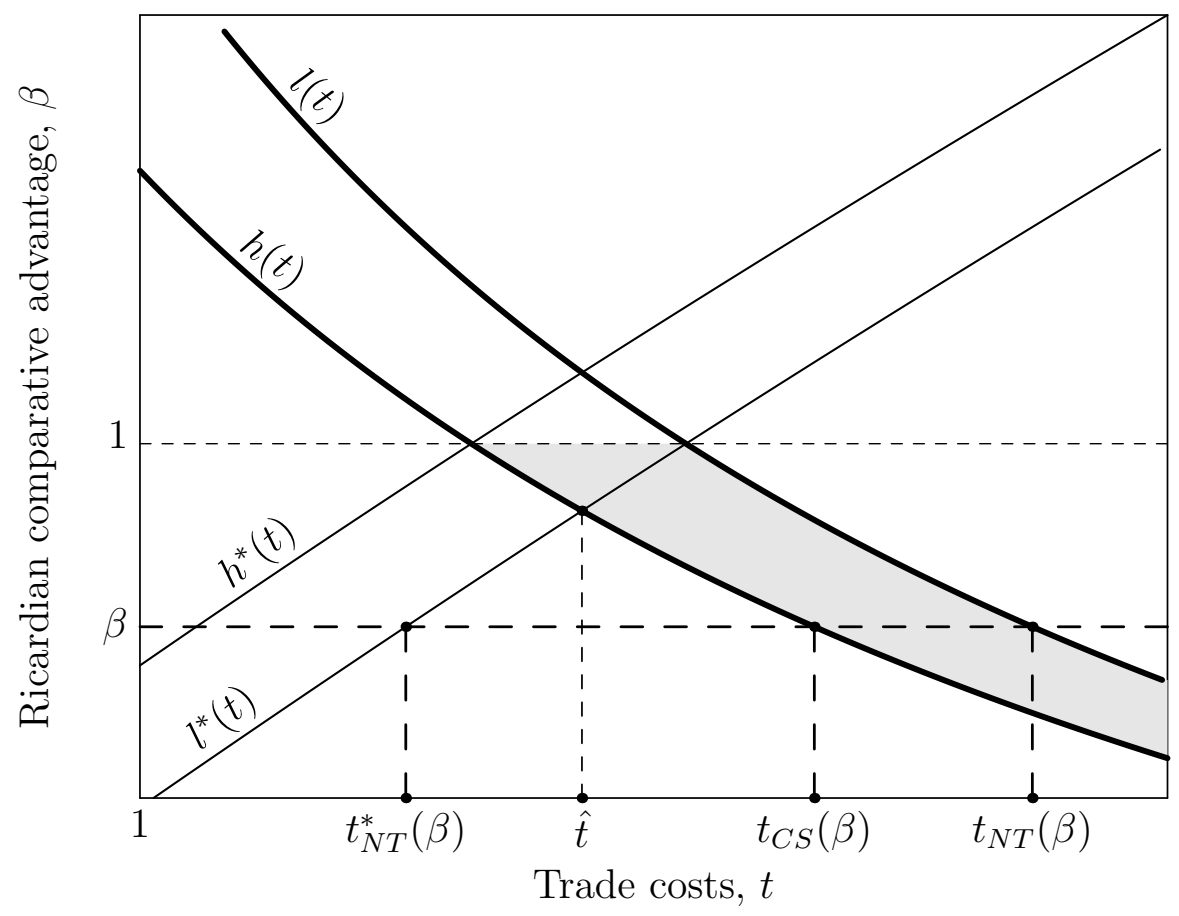

Figure III: Equilibrium with mixed strategies, $\phi=0.3$ 